\title{
Servant Leadership and the Effect of the Interaction Between Humility, Action, and Hierarchical Power on Follower Engagement
}

\author{
Milton Sousa $^{1} \cdot$ Dirk van Dierendonck ${ }^{2}$
}

Received: 24 January 2015/ Accepted: 13 June 2015/Published online: 2 July 2015

(c) The Author(s) 2015. This article is published with open access at Springerlink.com

\begin{abstract}
Servant leadership has been theorized as a model where the moral virtue of humility co-exists with action-driven behavior. This article provides an empirical study that tests how these two apparently paradoxical aspects of servant leadership interact in generating follower engagement, while considering the hierarchical power of the leader as a contingency variable. Through a three-way moderation model, a study was conducted based on a sample of 232 people working in a diverse range of companies. The first finding is that humble leaders showed the highest impact on follower engagement regardless of their hierarchical position. Less humble leaders in lower hierarchical positions seem to be able to compensate for that through a strong action-oriented leadership style. Most notably for leaders in high hierarchical positions, the moral virtue of humility seems to strengthen the impact of their action-oriented leadership the most. These findings provide empirical support and a better understanding of the interplay between the moral virtue of humility and the actionoriented behaviors of servant leadership.
\end{abstract}

Keywords Servant leadership · Virtue - Action · Humility $\cdot$ Power $\cdot$ Engagement

Milton Sousa

msousa@rsm.nl

Dirk van Dierendonck

dvandierendonck@rsm.nl

1 Rotterdam School of Management, Erasmus University, Burgemeester Oudlaan 50, J Building, 3062 PA Rotterdam, The Netherlands

2 Rotterdam School of Management, Erasmus University, PO Box 1738, 3000 DR Rotterdam, The Netherlands

\section{Introduction}

When servant leadership was first introduced through the seminal work of Greenleaf (1977), it brought a moral dimension to the leadership field, which for many years had been somehow subordinated to behavioral and contingency type of approaches (e.g., Fiedler 1967; Hersey and Blanchard 1969; Lewin et al. 1939). In a similar vein, Burns (1978) advanced the notion of transforming leadership that later evolved into transformational leadership, likewise with a strong moral emphasis and in contrast with transactional leadership (Bass 1985; Bass and Avolio 1994). Accelerated by the corporate scandals of the 1990s and 2000s (e.g., Adler 2002; Carson 2003; Crane and Matten 2007; Fombrun and Foss 2004), this moral side of leadership has gained interest as a way of ensuring performance while addressing ethical concerns in business, leading to the first empirical data on servant leadership (Russell and Stone 2002; van Dierendonck 2011), ethical leadership (Brown and Treviño 2006), and the birth of other theories like authentic (Gardner et al. 2005) or spiritual leadership (Fry 2003), to name a few. Additionally, scholars have recently tried to capture and operationalize this moral dimension of leadership into constructs of virtue (Arjoon 2000; Cameron 2011; Dale Thompson et al. 2008; Hackett and Wang 2012; Pearce et al. 2006). Virtues represent attributes of moral excellence, which aggregate into an overall dimension of virtuousness that can instill responsible leadership behavior (Cameron 2011). For Greenleaf (1977), this moral side or virtuousness was essential in forming the core motivation to serve of the servant leader, but it was not that morality should replace effective action, but instead that both should co-exist and reinforce each other. In practice, this translates into a dual mode of virtue and action which was captured, albeit not always explicitly, 
in some servant leadership models (e.g., Barbuto and Wheeler 2006; Dennis and Bocarnea 2005; Laub 1999; van Dierendonck 2011; van Dierendonck and Patterson 2015; Wong and Davey 2007). Most noticeably, the model of van Dierendonck (2011) makes this split between these two types of behaviors more apparent, with some empirical evidence of this being shown through a second-order factor analysis in a later study (van Dierendonck and Nuijten 2011). This study shows one cluster with the dimensions of humility and standing-back, which could be associated with a moral side and another cluster with the dimensions of empowerment, accountability, and stewardship, which could aggregate into an action side. Despite this co-existence, little is in fact known about how these two aspects interact with each other. Following on the work of Nielsen et al. (2010), who advanced a conceptual model whereby the follower attributions of the leader's humility would moderate the socialized charismatic leader's effectiveness in motivating followers, this study aims to further elaborate on this potential interaction for the specific case of servant leadership. The original question therefore that triggered this study was as follows: how does a humble attitude of being of service affect a servant leader's ability to instill effective action?

Knowing more about this interaction effect is important for two main reasons. First of all, it allows understanding leadership from within its complex behavioral relationships and not just as a linear aggregated concept. Secondly, it helps clarifying the apparently paradoxical mix of humble service and effective action, so markedly part of servant leadership (Morris et al. 2005; Patterson 2003; Russell 2001; van Dierendonck 2011) but also present in other models like authentic leadership, level 5 leadership, and transformational leadership (Morris et al. 2005).

Given also the potential interaction between power and humility (Collins 2001; Owens and Hekman 2012), we proposed to further investigate if the effect of a humble service attitude would be more salient for servant leaders in higher hierarchical positions of power in an organization. In sum, our study aims to confirm the three-way interaction between the action side of servant leadership (captured in the dimensions of empowerment, accountability and stewardship), the humble service-oriented side (captured in the dimensions of humility and standing-back), and the hierarchical rank of the leader in inducing follower engagement (see Fig. 1).

\section{Servant Leadership: A Balancing Act Between Humble Service and Action}

For Greenleaf (1977), the moral foundation of the servant leader is built on a motivation to serve. As eloquently put by Greenleaf himself (2002, p. 7), "The servant-leader is servant first... It begins with the natural feeling that one wants to serve, to serve first. Then conscious choice brings one to aspire to lead. That person is sharply different from one who is leader first, perhaps because of the need to assuage an unusual power drive or to acquire material possessions." However, while Greenleaf (1977) clearly highlighted the importance of the moral backbone of the servant leader, he also emphasized that being a servant leader is not the same as servitude and that such leaders need also to show initiative, assume risks and take ownership for action in order to be truly effective. The following statement testifies that "...the leader needs more than inspiration. A leader ventures to say, 'I will go; come with me!' A leader initiates, provides the ideas and the structure, and takes the risk of failure along with the chance of success." (Greenleaf 2002, p. 29). This means that servant leadership implies a balancing act between an overall humble attitude of service and behaviors that instill action and efficacy. So, whereas it may be possible to speak about servant leadership as one specific way of leadership, at a deeper level, and as mentioned before, there seem to be two overarching encompassing dimensions: a humble service-oriented side and an action-driven side, both co-existing and complementing each other.

While some measures (e.g., Liden et al. 2008; Sendjaya et al. 2008) put a stronger focus on moral, ethical, and service-oriented dimensions, a closer look at other servant leadership measures shows more or less explicitly these
Fig. 1 Conceptual three-way interaction

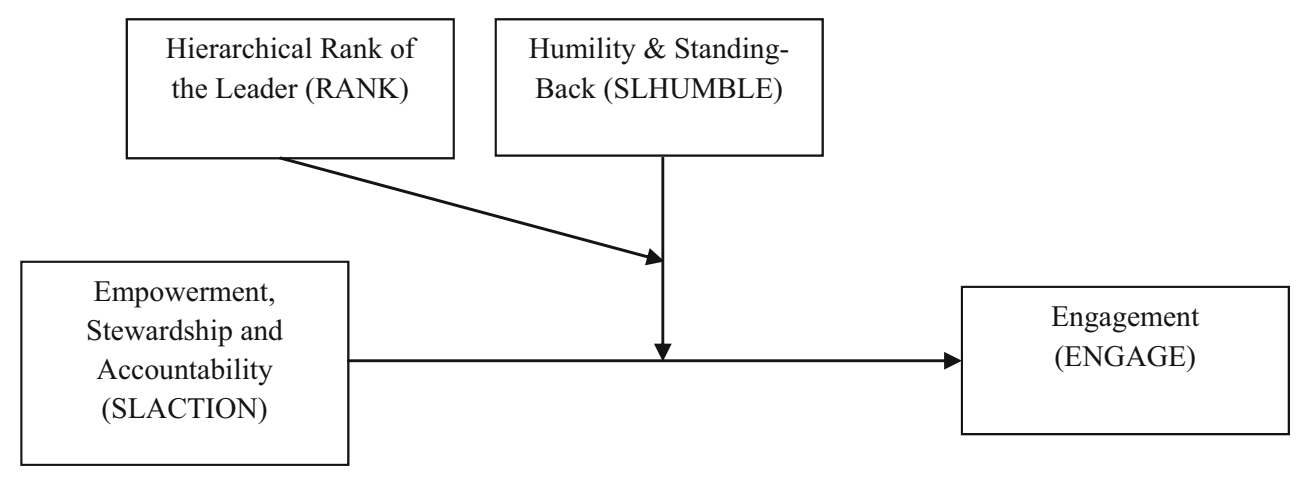


two sides of humble service and action-driven orientation, as shown ahead. For example, Laub's (1999) conceptual model and measure include both sharing and providing leadership. Sharing leadership requires accepting that others are equipped to take responsibility themselves, and therefore implies an overall attitude of humility with regard to the leader's own ability. At the same time, the servant leader is pro-active in providing leadership, not retracting from acting when necessary. Barbuto and Wheeler (2006) refer to both altruistic calling and stewardship. According to the authors, "altruistic calling describes a leader's deeprooted desire to make a positive difference in others' lives... Because the ultimate goal is to serve, leaders high in altruistic calling will put others' interests ahead of their own and will diligently work to meet followers' needs" (Barbuto and Wheeler 2006). Such selflessness can be translated into an attitude of humble service. At the same time, servant leaders are also stewards, ensuring that action is taken toward a greater purpose. Wong and Davey (2007) incorporate both humility and selflessness together with inspiring and influencing others while Dennis and Bocarnea (2005) mention both humility and vision. In both cases, there is an apparent dichotomy between humility and taking a pro-active role in setting direction and instilling action. In this regard, the Servant Leadership Survey (SLS) of van Dierendonck (2011) seems to be perhaps the one that most explicitly and accurately captures Greenleaf's original dual mode of humble service and effective action. Two particular studies (Asag-Gau and van Dierendonck 2011; van Dierendonck and Nuijten 2011) based on the SLS seem to confirm, through a second-order factor analysis, a potential sub-set of 5 core dimensions that could be split between humble service (humility and standing-back) and action (empowerment, accountability and stewardship). As such, our research was focused on this core set of 5 servant leadership behaviors and the potential interaction between the two sub-groups. The different dimensions will now be explained in more detail.

As mentioned before, humility forms the essential backbone of the servant leader (Patterson 2003; Russell 2001). As incorporated in the servant leadership construct of van Dierendonck (2011), humility is translated into three essential aspects: (1) the ability to put one's accomplishments and talents in perspective (Patterson 2003), (2) admitting one's fallibility and mistakes (Morris et al. 2005), and (3) understanding of one's strong and weak points. As such, "servant leaders acknowledge their limitations and therefore actively seek the contributions of others in order to overcome those limitations" (van Dierendonck and Nuijten 2011). Morris et al. (2005) suggested that humility "might be the operating mechanism through which servant leaders function" and that it forms the essential marker of a leader's motivation to serve.
Humility is further supported by the leader's ability of standing-back (van Dierendonck 2011), which "is about the extent to which a leader gives priority to the interest of others first and gives them the necessary support and credits... (and) is also about retreating into the background when a task has successfully been accomplished" (van Dierendonck and Nuijten 2011). Standing-back could be seen as a synonymous of modesty, which is essentially a "moderate estimation of one's merits and achievements" (Peterson and Seligman 2004, p. 463). As defended by several scholars (e.g., Morris et al. 2005; Nielsen et al. 2010; Peterson and Seligman 2004), humility and modesty are related constructs but differ insofar as humility is internally focused and modesty externally focused. As such, humility likely leads to modesty while the reverse might not always be true. For example, a leader could still acknowledge and give credit to others (modesty) while internally believing he or she was in fact the one responsible for success (no authentic humility). For this reason, we posit that an overall attitude of humble service will be reflected in both humility and modesty (or standing-back). Such position is in agreement with the findings of van Dierendonck (2011) where these measurement variables were combined into one overarching conceptual dimension. In summary, we suggest that humility and standingback are closely related dimensions underpinning the moral concern for others above the self, forming this way the fundamental foundation of the servant-first leader (the humble side).

The other 3 dimensions of servant leadership used in this study can be combined into a second overarching dimension of action. Starting with empowerment, this construct has many similarities with the notion of empowering leadership (Pearce and Sims 2002) and is essentially about encouraging autonomous decision making, sharing information, and the coaching and mentoring of individuals for increased innovative performance (Konczak et al. 2000). Accountability allows the servant leader to provide direction while considering the specific capabilities of people, as well as their particular needs and possible areas of contribution. In the end, accountability makes sure that people feel responsible for their results. This particular aspect is essential as a control mechanism for both performance management and learning. From all different servant leadership measures we identified, SLS is the only one that incorporates this essential control or feedback mechanism (van Dierendonck 2011). Finally, stewardship is a dimension that ensures that the common interest and the good of the whole are taken in account, while establishing a comprehensive framework for providing meaning to work and ensuring consistent action. In SLS, stewardship is the dimension that comes closer to the notion of vision or longterm orientation, which is essential in servant leadership 
(Dennis and Bocarnea 2005). One can already notice how these three servant leadership dimensions distinguish themselves from humility and standing-back in their action-oriented focus, as they all reflect behaviors that actively stimulate both individual and organizational performance while ensuring congruent direction. While humility and standing-back almost imply a detachment from action, these three highlight the servant leader's need to ensure pro-active involvement in setting course and facilitating others in their tasks. In light of this, we suggest that the three core dimensions of empowerment, stewardship, and accountability form the action-oriented side of the servant leader (the action side).

In summary, we suggest that the core set of five servant leadership dimensions as suggested by Asag-gau and Van Dierendonck (2011) can be split into a humble serviceoriented side, based on the dimensions of humility and standing-back, and an action side captured in the constructs of empowerment, stewardship, and accountability.

\section{The Relation Between Servant Leadership and Engagement}

Engagement is considered as the antithesis of burnout (Maslach et al. 2001). Schaufeli et al. (2006) characterize engaged employees as demonstrating behaviors of energy and connection to their work, while being able to deal well with the demands of their jobs. Schaufeli et al. (2006) further split engagement into three main components: vigor, dedication, and absorption. Vigor is shown by the energy and resilience demonstrated by workers and by their willingness and persistence in face of difficulties (Schaufeli et al. 2006). Dedication is explained by Schaufeli et al. (2006) as those behaviors that demonstrate a "sense of significance, enthusiasm, inspiration, pride, and challenge" in work. Finally, Schaufeli et al. (2006) advance that $a b$ sorption is reflected in the involvement shown in work, which can be characterized by a loss of a sense of time and an unwillingness to stop when working.

In recent years, several scholars have been able to empirically demonstrate the importance of engagement in generating organizational commitment (Hakanen et al. 2006) and work performance (Bakker and Bal 2010; Xanthopoulou et al. 2009). Other studies, more focused on aspects of personal well-being, have shown how engagement can contribute toward higher levels of psychological soundness (Demerouti et al. 2001; Schaufeli and Bakker 2004; Schaufeli et al. 2008; Xanthopoulou et al. 2009). When looking at the antecedents of engagement, Bakker and Demerouti (2007) advanced two key individual aspects that positively contribute to engagement: first, through the available job resources reflected in aspects like organizational support, management feedback or the level of autonomy, among others, and secondly through personal resources such as resilience, self-efficacy or optimism. At the same time, Bakker and Demerouti (2007) suggest that engagement will be negatively influenced by the level of job demands, including aspects like work pressure and the emotional, mental, and physical demands of the work at hand.

When looking at the antecedents presented before, one can see servant leadership as potentially playing an important role in creating the conditions for engagement to flourish in organizations. Servant leadership is oriented to the followers' needs and development (van Dierendonck 2011) through pro-active individual support and the creation of a work environment that fosters personal growth. This communicates to followers that the organization, in the person of the leader, cares about them and stimulates their development through their own work. For the servant leader, work is an instrument of personal growth and realization through which the organization fulfills both its business and social mission. In essence, servant leaders have a "other" focus as opposed to a "self" focus (Morris et al. 2005), which is reflected on serving both the employees of the organization and its external stakeholders. Such a serving and empowering attitude can be inductive of engagement as demonstrated in different empirical studies. For instance, Schaufeli and Bakker (2004) argued that a social supportive work environment reduces job demands, helps in achieving work goals, and stimulates personal growth, learning, and development which are all part of servant leadership. In an extensive study to validate their new measure of servant leadership, van Dierendonck and Nuijten (2011) found supporting evidence for the potential impact of servant leadership on workforce engagement. In other empirical studies, aspects closely related to servant leadership like humility (Owens et al. 2013) and empowerment (Tuckey et al. 2012) were also found to be strongly related to engagement. We therefore suggest that both the action side and the humble side of the servant leader as advanced before will be positively related to engagement, which constitutes our first hypothesis.

Hypothesis 1 Both the action side and the humble side of servant leadership will have a significant impact on the overall level of work engagement among followers.

\section{The Amplifying Effect of Attributed Humility on Leadership Effectiveness}

The etymological origin of humility is based on the Latin word humilis (on the ground) which is derived from the word humus (earth) (Online Etymology Dictionary 2010). 
In this sense, one can say that humility literally brings someone down to earth. In accordance, humility was qualified by Park and Peterson (2003) as a temperance virtue that grounds and stabilizes one's self-perception. Grenberg (2005) further suggests that humility is a sort of meta-virtue sustaining other virtues like forgiveness, courage, wisdom, and compassion, while Morris et al. (2005) define humility "as a personal orientation founded on a willingness to see the self accurately and a propensity to put oneself in perspective."

The importance of humility for leaders was captured by scholars like van Dierendonck and Patterson (2015), Morris et al. (2005), Nielsen et al. (2010), and Snyder (2010). In particular, humility seems to be essential in keeping the leader's achievements and strengths in perspective, while focusing more on others than on self-interest (Morris et al. 2005; Fairholm and Fairholm 2000; Sandage and Wiens 2001), which is congruent with the tempering effect suggested by Park and Peterson (2003) and Morris et al. (2005). In addition, van Dierendonck and Patterson (2015) propose that the virtuous attitude of servant leaders, based on humility, gratitude, forgiveness, and altruism, will give rise to other behaviors like empowerment, stewardship or providing direction.

Owens and Hekman (2012) propose that the leader's humility can be split essentially around "three categories: (1) acknowledging personal limits, (2) spotlighting followers' strengths and contributions, and (3) modeling teachability." In a later study, these three categories have been captured in a quantitative instrument of leader expressed humility, which was shown to correlate with aspects like job engagement, job satisfaction, and team learning goal orientation (Owens et al. 2013). One can observe that these three aspects suggested by Owens and Hekman (2012) coincide in many ways with the combined notions of humility and standing-back presented before (underpinning the humble service side). As suggested by van Dierendonck (2011), these two dimensions are reflected in putting one's accomplishments and talents in perspective, admitting one's errors, understanding own strengths and weaknesses, and valorizing the strengths and achievements of others. Based on an empirical qualitative study, Owens and Hekman (2012) further propose that a leader's humble behaviors can have two main outcomes: (1) at the individual level, it can increase the sense of personal freedom and engagement among followers by legitimizing their developmental journey, and (2) at the organizational level, it increases the fluidity of the organization by legitimizing uncertainty. This emphasizes that the leader's humility can affect performance both by improving the quality of the leader-follower relationship (individual level) and through the creation of a learning and adaptive organization (systemic level). Based on these conceptualizations and empirical findings, it seems that humility operates on the leader's effectiveness at multiple levels, but its specific mechanisms still seem somehow unclear, both in terms of the internal psychological processes of the leader and in terms of the psychological effect that perceived humility can create in the follower. The work of Nielsen et al. (2010) might provide some interesting clues into this.

Taking a socialized charismatic leadership model, Nielsen et al. (2010) conceptualize that humility can support a leader's effectiveness from two perspectives. First of all, it can improve the ability of leaders to generate, implement, and communicate their vision. From this angle, humility is seen as an internal and personal character trait (Vera and Rodriguez-Lopez 2004) that will help the leader incorporate the followers' viewpoints, self-concepts, and needs while keeping the leader grounded, hereby improving the quality of the leader's aforementioned visioning behaviors (Nielsen et al. 2010). Secondly, the follower attributions of the leader's humility (i.e., being perceived as humble) will function as a "critical moderator, either strengthening or weakening the relationship between" these visioning behaviors and diverse follower outcomes, including motivation and willingness to sacrifice (Nielsen et al. 2010). Such amplification effect of the attribution of humility is essentially driven by an increased perception of trustworthiness, honesty, confidence, and competence, inducing greater "loyalty and trust in the leader, which will in turn inspire greater willingness and commitment to following the leader's vision" (Nielsen et al. 2010). Here, it is not so much about the actual humility of the leader but instead the perceived humility as seen by the followers, and how it enlarges the feeling of trust toward the leader. It is important to note that while Nielsen et al. (2010) incorporate these direct and indirect effects of leader humility and follower attributed leader humility within the model of socialized charismatic leadership, they contend that similar assertions could be made for servant leadership.

Measuring actual humility is quite hard. Comte-Sponville (2001) and Richards (1992) remind us that humble people will most likely not call themselves humble, so selfassessments will always be poor indicators of humility. While one could operationalize actual humility as the gap between self and other evaluations (Rowatt et al. 2002), this was beyond the scope of our study and we concentrated instead on the assessment of perceived humility and the close companion of standing-back (or modesty) as seen by the followers, which amounts to the notion of attributions of humility as suggested by Nielsen et al. (2010). Based on these considerations, we suggest that the humble service side of servant leaders (as perceived by followers) can work as catalyst of their action side by improving the relationship of trust with followers. This interaction 
between the humble side and the action side of servant leadership and the impact on the motivational construct of engagement form the second hypothesis of this study:

Hypothesis 2 The humble service side of servant leadership (as perceived by followers) will work as moderating variable by amplifying the effect of the action side on work engagement among followers.

\section{Hierarchical Power as a Contingency Factor}

Power and leadership are strongly interrelated, which are evident in the different definitions given for these two concepts. For example, Stoner and Freeman (1985) define power essentially as the capacity to influence and shape the behaviors and attitudes of individuals and groups. On the other hand, Yukl (2006, p. 8) defines leadership as "the process of influencing others to understand and agree about what needs to be done and how to do it, and the process of facilitating individual and collective efforts to accomplish shared objectives". Both definitions share that influence is the essential defining element of both constructs. From a systemic point of view however, the difference seems to rely on the fact that power is seen as a potential to influence (a relatively stable measure of potency), while leadership seems to be more associated with the process and dynamics to exercise that influence (the behaviors that are conductive of exercising that influencing power). One's level of power will influence one's ability to lead and of course, effective leadership will increase one's power or potential to influence, in a positive and reinforcing feedback loop.

French and Raven (1959) advanced that power can have 5 bases or sources. These evolved later to 6 bases (Raven 1965), namely coercion (the ability to influence based on the possibility of punishment or penalty), reward (the power to compensate for achieving certain targets), legitimacy (power based on a certain recognized right to influence, like, for example, a job title), expertise (based on the perception about one's level of knowledge and skills for a certain job), reference (power that stems from a strong sense of identification and admiration), and information (essentially the capacity to communicate either through logical or emotional reasoning, eloquence, or charisma). The stronger these bases, the more the power one possesses. We theorize that the moderating role of follower attributions of leader humility will be more salient for leaders with stronger power bases. In other words, the more power the leader possesses, the more followers will value his or her humility, hence increasing their motivation to follow. This, we posit, emerges from two aspects. First, humility will be seen as a good and positive trait, once power is legitimate and recognized, as it testifies that the leader is working beyond self-interest and focusing on others. Secondly, under the same conditions of legitimate and recognized power, humility will create a sense of closeness and proximity whereby the leader becomes "one of us." In other words, there is an aspirational element where the follower becomes one with the leader through his or her humility.

Some scholars seem to refer to similar effects, albeit in different terms. For example, when elaborating on the positive impact of humility on the leader's effectiveness, Owens and Hekman (2012) advance possible contingency factors that might condition this impact. One of these factors is the level of perceived competence, which is similar to French and Raven's (1959) expert power, felt by followers with regard to the leader. Based on several interviews conducted in a qualitative study, it becomes apparent that humility is only effective when followers recognize that the leader is competent and able (Owens and Hekman 2012). In addition, for leaders in higher ranks (CEOs and executives), "competence... would be less likely to be called into question than would be likely in the case of a lower-level leader" (Owens and Hekman 2012). This essentially could mean, as we suggested earlier, that the amplifying effect of humility will be stronger for leaders in upper ranks with more power and implicitly more competent.

A similar possibility seems to be implicit in Collins' (2001) leadership model, which is based on 5 levels. Level 1 is called the "Highly Capable Individual," essentially based on a contribution through talent, knowledge, skills, and good work habits. Level 2 further adds the ability of the individual to contribute toward team objectives and to work effectively with team members. This level is called the "Contributing Team Member." At level 3, there is a stronger component of management of both people and resources toward the organization's objectives. Collins (2001) calls this the "Competent Manager." Level 4, the "Effective Leader," adds the ability of the leader to generate commitment toward a compelling vision and highperformance standards. Finally, at level 5, the "Executive" is able to endure greatness through what Collins (2001) calls a paradoxical mix between a strong professional will and humility. While such levels do not necessarily have to correspond to positions of power in the organization, they seem to provide a natural ranking as people move from professionals and team members to middle, senior, and executive management positions, with humility gaining relevance at the highest level to explain their effectiveness. This could mean again that humility will be most salient for leaders in higher positions of power.

Our third hypothesis captures this potential indirect effect of hierarchical power, moderating the effect of humility on leadership effectiveness, as formulated below. 
Hypothesis 3 The higher the hierarchical power position of the leader, the stronger will be the amplifying effect of the humble side of servant leadership on the relation between the action side and engagement among followers.

\section{Methods}

\section{Subjects}

Participants were employees from a varied range of organizations in Portugal from different sectors. A total of 236 people answered the survey in different hierarchical positions. $56.3 \%$ of the sample was male and $43.7 \%$ female. $44.1 \%$ of respondents were between 35 - and 44-year old, $31.9 \%$ between 25 and $34,16.4 \%$ between 45 and 54 , $5.9 \%$ higher than 55 and $1.7 \%$ below 25 -year old. In terms of their distribution in hierarchical ranking, $2.9 \%$ were at board level, $34.0 \%$ at director level, $24.0 \%$ at senior management level, $11.8 \%$ at junior management level, $20.6 \%$ at intermediate non-managerial level, and another $2.9 \%$ as junior professionals. 2 respondents answered as being freelancers and 2 others as unemployed. In order to ensure that all participants were currently in a stable job and reporting to a direct manager, these 4 persons were taken out of the sample, giving a sample size of 232 persons. In terms of size of the organizational they worked in, the sample was quite fairly distributed, with $29.4 \%$ of respondents being from organizations bigger than 1000 people, $24.0 \%$ between 250 and $999,21.4 \%$ between 50 and 249, $16.8 \%$ between 10 and 49 , and $8.4 \%$ below 10 people.

\section{Measures}

\section{Servant Leadership}

All participants reported on how they perceived the leadership behaviors of their direct manager through items taken from the Servant Leadership Survey developed by van Dierendonck and Nuijten (2011). A 7-point Likert scale was used ranging from 1 (completely disagree) to 7 (completely agree). In order to further attest the quality of our model splitting the humble and action sides, discriminant validity of the servant leadership measure was tested through confirmatory factorial analysis with Mplus 6.1 (Muthén and Muthén 2009). Three models were tested: (i) a one-dimensional model with all items loading on a single servant leadership variable; (ii) a 5-dimensional model with a second-order servant leadership variable; and (iii) a 5-dimensional model with two second-order variables capturing humility and standing-back (SLHUMBLE) and empowerment, accountability, and stewardship
(SLACTION). The fit indices for the 5-dimensional model loading on one second-order servant leadership variable $\left(X^{2}=494.56, \quad d f=184, \quad \mathrm{CFI}=.92, \quad \mathrm{TLI}=.91\right.$, RMSEA $=.09$, SRMR $=.05$ ) were very similar to the model with the split between SLACTION and SLHUMBLE $\left(X^{2}=493.20, d f=183, \quad\right.$ CFI $=.92, \quad$ TLI $=.91$, RMSEA $=.09$, SRMR $=.05$ ). Both showed significantly better fit indices than the one-dimensional model $\left(X^{2}=811.93, \quad d f=189, \quad \mathrm{CFI}=.85, \quad \mathrm{TLI}=.83\right.$, RMSEA $=.12$, SRMR $=.06$ ), confirming the discriminant validity of the multi-dimensional measure used for this study and the potential split into two underlying dimensions of an humble service attitude and an action orientation.

Once the discriminant validity of the measure was tested, the items related to stewardship (3 items), accountability ( 3 items), and empowerment ( 7 items) were composed into the action-side measure of servant leadership (captured in a variable called SLACTION). The internal consistency of this overall measure was .94 with the 13 items. On the other hand, the items of humility (5 items) and standing-back ( 3 items) were composed into one humble-side dimension of servant leadership (captured in a variable named SLHUMBLE). The internal consistency of this measure was .93 with the 8 items. According to Nunnally (1978) and Kline (1999), a Cronbach alpha of .70 is acceptable for a survey, meaning that the scores for both SLACTION and SLHUMBLE are very good.

\section{Engagement}

The short version of the Utrecht Work Engagement Scale by Schaufeli et al. (2002) was used. The scale includes 9 self-assessment items on vigor, dedication, and absorption. Ratings were given on a 7-point Likert scale, ranging from 1 (completely disagree) to 7 (completely agree). Results were composed into one single indicator of engagement (the variable was called ENGAGE) with an overall internal consistency of .94 , which is again a very good score.

\section{Hierarchical Power}

Instead of measuring perceived power through a survey, our approach was instead to assess power through the hierarchical level of the respondent (and implicitly, their leader). In this study, our intention was not to dissect the different aspects of power and their relation to humility but instead get a first indication of how hierarchy (as a proxy of organizational power) affects this relationship. This approach has two other advantages. Firstly, it allowed reducing the survey size substantially and increases this way the response rate. Secondly, as the question on hierarchical level is objective and based on the participant's 
actual position, it reduces concerns on common-method bias, whereby the assessment of perceived power would be conditioned by the answers given on servant leadership behavior. In order to determine the hierarchical position in their organization, participants were asked to classify their current rank according to 6 possible categories: board level (1), director level (2), senior management level (3), junior management level (4), intermediate non-managerial level (5), and junior professional (6). Logically, it follows that the participant's leader is either at the same level or a level above. For this particular study, it was critical to ensure that the sample included people currently employed such that their relative position in the hierarchical rank could be determined. 4 participants responded "other" but did provide a detailed job title which allowed re-classifying them according to the 6 categories. The hierarchical position, as a proxy of organizational power, was captured in a variable called RANK.

\section{Results}

\section{The Regression Models}

In order to validate the three hypotheses advanced before, three analytical steps were conducted based on a multiple linear regression, a single moderation model, and a model with two moderators (where the second moderator interacts with the first moderation) as suggested by Hayes (2013). Further details and respective results of this study are provided next.

Table 1 shows the mean values, standard deviations, and intercorrelations of the variables of the study. As mentioned before, in order to validate the three hypotheses advanced before, three regression analytical steps were conducted. In order to test the first hypotheses, a multiple linear regression analysis was done, with SLACTION, SLHUMBLE, and RANK as independent variables and ENGAGE as dependent variable. For the second hypotheses, a bootstrapping technique was used in SPSS using model 1 of the PROCESS script as provided by Hayes (2013). This single moderation model incorporated

Table 1 Descriptives and intercorrelations of study variables

\begin{tabular}{llllll}
\hline & Mean & SD & 1 & 2 & 3 \\
\hline SLACTION & 4.98 & 1.20 & & & \\
SLHUMBLE & 4.17 & 1.37 & $.85^{* *}$ & & \\
ENGAGE & 5.41 & 1.10 & $.55^{* *}$ & $.54^{* *}$ & \\
RANK & 3.25 & 1.31 & $-.17^{* *}$ & $-.16^{*}$ & $-.35^{* *}$ \\
\hline
\end{tabular}

$n=232$. RANK is in reversed order (lower numbers $=$ higher ranks)

$* p<.05, * * p<.01$
SLACTION as an independent variable, SLHUMBLE as moderating variable, ENGAGE as a dependent variable, and RANK as a covariate. This model allowed interpreting the conditional effect of the two-way interaction between SLACTION and SLHUMBLE. Finally, in order to test the third hypotheses, the same bootstrapping technique was used in SPSS but using model 3 of the PROCESS script as provided by Hayes (2013). This model was tested by having SLACTION as an independent variable, SLHUMBLE as primary moderating variable, RANK as a secondary moderating variable (interacting with SLHUMBLE), and ENGAGE as dependent variable (Fig. 1). This allowed observing the conditional effect of the three-way interaction between SLACTION, SLHUMBLE, and RANK. We will now present the results of these three analytical steps.

\section{Results of the Three Analytical Steps}

Table 2 shows the results for the different steps, including the coefficients and the statistical significance of the twoway and three-way interactions.

As can be seen in Table 2, when considering SLACTION $(b=.286, \quad$ se $=.091, \quad p<.01), \quad$ SLHUMBLE $(b=.184$, se $=.080, p<.05)$, and RANK $(b=-.214$, se $=.044, p<.01)$ as independent variables in a multiple linear regression, the model accounts for $38.45 \%$ of the variance on engagement. Step 2 adds the two-way interaction between SLACTION and SLHUMBLE in a single moderation, which is statistically not significant ( $b=-.015$, se $=.033, p=.653$ ), leaving the overall $\mathrm{R}^{2}$ practically unchanged when compared to the previous step. With step 3, we incorporated the three-way interaction between SLACTION, SLHUMBLE, and RANK. This three-way interaction was found to be statistically significant $(b=-.061$, se $=.025, p<.05)$, with a $95 \%$ confidence interval between -.11 and -.012 , meaning that we are at least $95 \%$ certain that the interaction coefficient is not zero. This three-way interaction accounts for an additional $1.61 \%$ of the variance of the model (incremental $R^{2}$ ), with a total $R^{2}$ of .405 .

The diagram on Fig. 2 allows observing the effect of the three-way interaction on the impact of the action side of servant leadership on engagement for different hierarchical ranks (high, medium, and low). The first observation is that humility seems to have always a positive impact on engagement regardless of the hierarchical position of the leader. In addition, for higher ranks, the humble side will increase significantly the effect of the action side on engagement. Finally, for lower ranks, less humble leaders seem to be able to compensate for this by having a strong action-oriented leadership. As for medium ranks, although it is evident that the humble side positively affects 
Table 2 Regression results

\begin{tabular}{lccc}
\hline & Step 1 Betas & Step 2 Betas & Step 3 Betas \\
\hline Intercept & $3.91^{* *}$ & $6.12^{* *}$ & $5.43^{* *}$ \\
SLACTION & $.29 * *$ & $.27 * *$ & $.29 * *$ \\
SLHUMBLE & $.19 *$ & $.19 *$ & .15 \\
RANK & $3.91^{* *}$ & $-.21^{* *}$ & $-.13^{*}$ \\
SLACTION $\times$ SLHUMBLE & & -.02 & $<.00$ \\
SLACTION $\times$ RANK & & & $<.00$ \\
SLHUMBLE $\times$ RANK & & & $<.00$ \\
SLACTION $\times$ SLHUMBLExRANK & & & $-.06^{*}$ \\
$R$ & .62 & .62 & .64 \\
$R$-sq & .39 & .39 & .41 \\
$F$ & $47.48^{* *}$ & $35.54 * *$ & $21.78^{* *}$ \\
$\Delta R$-sq & & $<.00$ & .02 \\
$F$ & & .20 & $6.05^{*}$ \\
\hline
\end{tabular}

$* * p<.01, * p<.05$

engagement, it does not change the nature of the relation between the action side and this motivational construct.

When probing the interaction for different moderator values (see Table 3), one can observe that the conditional effect of the action side is significant for most points (results were mean centered to ease interpretation). The changes in the conditional effects clearly show how the three-way interaction affects the relationship between the action side and engagement, as explained above. Using the Johnson-Neyman technique (Bauer and Curran, 2005), the significance region for the three-way interaction is given for mean-centered values of SLHUMBLE below -2.141 (high ranks) and above 1.497 (low ranks), which is consistent with the previous analysis.

\section{Discussion}

This study provides two important contributions. First of all, it contributes to a better understanding of servant leadership by showing how the humble and action-oriented dimensions of the servant leader can interact to affect motivation (engagement in our case). As described in this article, the humble side can be captured in an overarching service attitude through humility and standing-back, and the action side through aspects like empowerment, accountability, and stewardship. This comes to sustain the potential split of the different dimensions of servant leadership as advanced by van Dierendonck and Nuijten (2011) and the original thinking of Greenleaf (1977) whereby servant leadership entails both a moral concern for serving people (the virtue of humility) and the ability to mobilize them for performance and growth (action). At the same time, the positive impact of servant leadership on engagement is once again confirmed through an empirical study, further supporting previous findings (van Dierendonck and Nuijten 2011) and our first hypothesis.

Secondly, this article contributes to comprehending the potential role of hierarchical power in explaining the interaction between the humble and action sides of servant leadership. More specifically, we were able to provide empirical evidence on the amplifying effect of the humble side of the servant leader on leadership effectiveness. This was reflected in an increased impact of the action side on engagement for leaders in higher ranks (hence with more hierarchical power). These findings seem to confirm previous theorizing on the indirect moderating effect of attributed humility on leadership effectiveness (Nielsen et al. 2010) mainly for leaders in higher positions of power, supporting similar assertions by Collins (2001) and Owens and Hekman (2012). For lower ranks, humility still seems to play an important role in ensuring engagement (although with lower overall impact than in higher ranks). It is worth to note that less humble leaders at the lower levels of the hierarchy still seem able to compensate for this through a strong action-oriented leadership style. Something of this nature has been suggested by Nielsen et al. (2010), where attributions of humility could have a negative effect for certain types of leadership, namely for transactional leaders in opposition to transformational leaders (Bass 1985). This could very well be the process in place here, where leaders in lower ranks due to their operational focus would make more use of transactional leadership mechanisms. This might raise the possibility that, in its fullness, servant leadership could be a model particularly effective for executive and board-level functions and maybe less so for more practical hands-on line management positions. In 

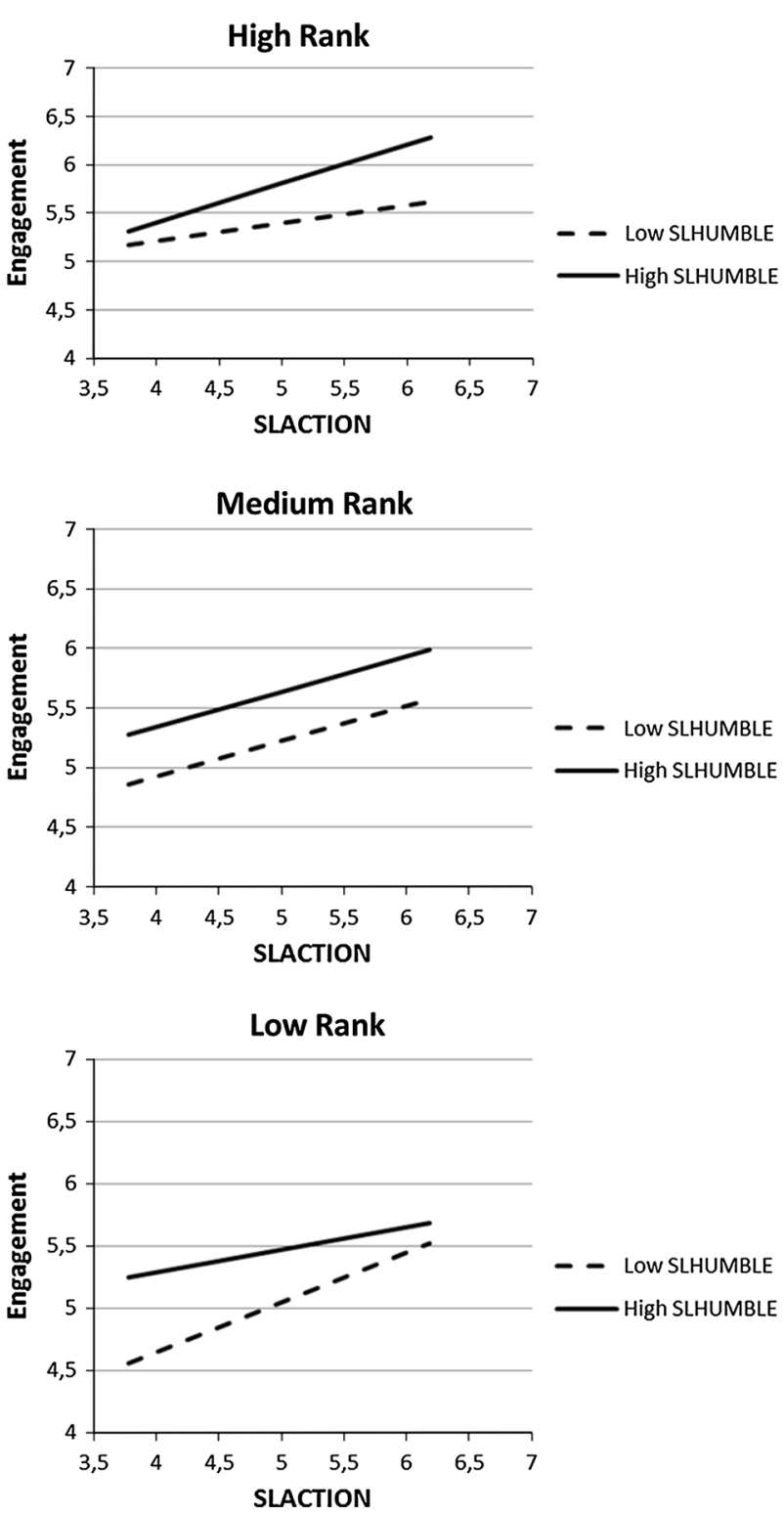

Fig. 2 Effect of the three-way interaction between SLACTION, SLHUMBLE, and RANK

other words, the combination of humility and action seems to be most effective for senior executives.

Going in more detail into the three hypotheses of this study, one can advance the following conclusions. First of all, as seen in the correlation figures of Table 1 and the multiple linear regression analysis of Table 2, both the action and humble sides of servant leadership seem to have a significant effect on engagement, confirming our first hypothesis. When considering a single interaction, we cannot observe an amplifying effect of the humble side of the servant leader on the impact of the action side on engagement, which does not allow us to confirm hypothesis 2. However, when the hierarchical rank is introduced as a
Table 3 Conditional effects for different values of the moderators using PROCESS by Hayes (2013)

\begin{tabular}{lccccccc}
\hline RANK & SLHUMBLE & Effect & SE & $T$ & $p$ & LLCI & ULCI \\
\hline-1.31 & -1.37 & .19 & .13 & 1.45 & .15 & -.07 & .44 \\
-1.31 & .00 & .30 & .14 & 2.08 & .04 & .02 & .58 \\
-1.31 & 1.37 & .40 & .18 & 2.23 & .03 & .05 & .76 \\
.00 & -1.37 & .29 & .09 & 3.21 & .00 & .11 & .47 \\
.00 & .00 & .29 & .10 & 2.96 & .00 & .10 & .49 \\
.00 & 1.37 & .29 & .12 & 2.36 & .02 & .05 & .54 \\
1.31 & -1.37 & .40 & .13 & 3.20 & .00 & .15 & .65 \\
1.31 & .00 & .29 & .13 & 2.23 & .03 & .03 & .55 \\
\hline
\end{tabular}

Values are mean-centered. RANK is in reversed order (lower numbers $=$ higher ranks)

secondary moderating variable, we observe a significant three-way interaction where the humble side of the servant leader significantly amplifies the effect of the action side on follower engagement for leaders in higher ranks at board and executive level, which confirms hypothesis 3 . The fact that the amplifying effect of the humble side only becomes visible when the hierarchical rank is introduced in a threeway regression model comes to demonstrate the importance of incorporating additional contingency variables in the further study of servant leadership and the specific mechanisms through which it can affect performance.

Some further considerations are important. While our study seems to indicate that there is indeed an indirect moderating effect of attributed humility on leadership performance especially for leaders in higher position of power, the mechanism through which that happens remains to be explored. We support the idea that attributions of humility will increase trustworthiness, as suggested by Nielsen et al. (2010). Trust is related to the level of confidence that an individual has toward another's competence and willingness to act fairly, ethically, and in a predictable way (Nyhan 2000). How perceptions of humility affect these different aspects of trust is something that deserves attention and should be included in future research.

One other aspect that deserves some attention relates to the fact that our study concentrates on follower attributions of humility and standing-back (the aggregate humble side), which addresses the indirect effect on leadership effectiveness suggested by Nielsen et al. (2010). Incorporating measures of actual humility would be an important addition for a wider comprehension of the overall effect of this construct (actual and perceived) on leadership effectiveness. Given the difficulties of measuring actual humility with self-assessments alone (Comte-Sponville 2001; Richards 1992), future studies could incorporate new methods such as mapping the gap between self and other evaluations of leadership behaviors (Rowatt et al. 2002). 
Studies on self-other agreement (SOA) might provide also interesting clues in this regard (Atwater et al. 1998).

When looking at possible limitations of this study, we acknowledge that national culture should be considered as potential moderator (Morris et al. 2005) as it can have a significant influence on perceptions about humility, power, and leadership (Hofstede 1983, 1993; Hofstede et al. 2010; House et al. 2002, 2004). Interestingly, some scholars contended that humility would be more accepted in countries with low power distance (Kets 2004; Peterson and Seligman 2004), but our study seems to show that also in a country with relatively high power distance like Portugal (Hofstede n.d.), humility still seems to have a positive effect. On the other hand, Morris et al. (2005) further suggest that feminine societies, like the Portuguese one (Hofstede n.d.) might be more open toward behaviors of humility than masculine societies. Given this apparent lack of clarity, future research would certainly be welcome to address these concerns by for example incorporating measures of national culture as a moderating variable.

One additional note concerns our approach toward measuring power. The hierarchical level of the respondent has been used as an indirect proxy of the leader's power in an organizational hierarchical setup. While this has the advantage of reducing common-method bias concerns as it is an objective measure (Chang et al. 2010), we acknowledge that it is indeed a rather rough indicator of power prone to some level of error. We suggest that future research includes a measure of power bases (e.g., Rahim 1988), assessed in a separate moment to reduce again concerns with common-method bias that would allow distinguishing the specific impact of the different sources of power on the relationship between humility and leadership effectiveness.

Another possible limitation is the cross-sectional character of the study. However, in addition to the measures taken to reduce common-method bias explained before, it has been shown that within regression analysis, artificial interactions caused by common-method bias are unlikely (Evans 1985). These and other studies actually warn against the very real possibility of Type 2 errors when trying to detect interaction effects. A rough rule suggested by Evans (1985) is to take $1 \%$ of the explained variance as the criterion as to whether a significant effect exists. With additional explained variance of approximately $2 \%$ for the three-way interaction on employee engagement, this criterion was met.

\section{Conclusion}

In conclusion, the results of our study are quite promising as they seem to provide quantitative empirical evidence on the potential split between the humble and action sides of servant leadership (Greenleaf 1977; van Dierendonck and Nuijten 2011). At the same time, evidence is given on the specific workings of humility, and the accompanying behavior of standing-back, on leadership effectiveness, while incorporating the specific role of hierarchical power as a contingency variable, further sustaining the propositions suggested by Owens and Hekman (2012) and Nielsen et al. (2010). Our findings suggest that the combination of humility and action is most potent in generating engagement at the higher hierarchical ranks. This could lead us to conclude that in its wholeness, servant leadership might be particularly effective for leaders in executive and boardlevel positions. On the other hand, for managers working at lower levels in the organization, maybe more operational, the action side of servant leadership might suffice in generating engagement. As a final note, our study comes to confirm the comprehensive reach and applicability of the servant leadership model developed by van Dierendonck (2011), adequately capturing the multiple and complex set of virtues and action-oriented behaviors of leadership in driving performance in different contexts and situations.

Open Access This article is distributed under the terms of the Creative Commons Attribution 4.0 International License (http://creativecommons.org/licenses/by/4.0/), which permits unrestricted use, distribution, and reproduction in any medium, provided you give appropriate credit to the original author(s) and the source, provide a link to the Creative Commons license, and indicate if changes were made.

\section{References}

Adler, P. S. (2002). Corporate scandals: It's time for reflection in business schools. The Academy of Management Executive, 16(3), $148-149$.

Arjoon, S. (2000). Virtue theory as a dynamic theory of business. Journal of Business Ethics, 28(1), 159-178.

Asag-Gau, L., \& van Dierendonck, D. (2011). The impact of servant leadership on organisational commitment among the highly talented: The role of challenging work conditions and psychological empowerment. European Journal of International Management, 5(5), 463-483.

Atwater, L. E., Ostroff, C., Yammarino, F. J., \& Fleenor, J. W. (1998). Self-other agreement: Does it really matter? Personnel Psychology, 51(3), 577-598.

Bakker, A. B., \& Bal, P. M. (2010). Weekly work engagement and performance: A study among starting teachers. Journal of Occupational and Organizational Psychology, 83, 189-206.

Bakker, A. B., \& Demerouti, E. (2007). The job demands-resources model: State of the art. Journal of Managerial Psychology, 22, 309-328.

Barbuto, J. E., \& Wheeler, D. W. (2006). Scale development and construct clarification of servant leadership. Group and Organization Management, 31(3), 300-326.

Bass, B. M. (1985). Leadership and performance. New York: Free Press.

Bass, B. M., \& Avolio, B. J. (Eds.). (1994). Improving organizational effectiveness through transformational leadership. Thousand Oaks, CA: Sage Publications. 
Bauer, D. J., \& Curran, P. J. (2005). Probing interactions in fixed and multilevel regression: Inferential and graphical techniques. Multivariate Behavioral Research, 40(3), 373-400.

Brown, M. E., \& Treviño, L. K. (2006). Ethical leadership: A review and future directions. The Leadership Quarterly, 17(6), 595-616.

Burns, J. M. (1978). Leadership. New York: Harper and Row.

Cameron, K. (2011). Responsible leadership as virtuous leadership. Journal of Business Ethics, 98(1), 25-35.

Carson, T. L. (2003). Self-interest and business ethics: Some lessons of the recent corporate scandals. Journal of Business Ethics, 43(4), 389-394.

Chang, S. J., van Witteloostuijn, A., \& Eden, L. (2010). From the editors: Common method variance in international business research. Journal of International Business Studies, 41(2), 178-184.

Collins, J. (2001). Level 5 leadership: The triumph of humility and fierce resolve. Harvard Business Review, 79(1), 67-76.

Comte-Sponville, A. (2001). A small treatise on the great virtues. New York: Henry Holt and Company.

Crane, A., \& Matten, D. (2007). Business ethics: Managing corporate citizenship and sustainability in the age of globalization. Oxford: Oxford University Press.

Dale Thompson, A., Grahek, M., Phillips, R. E., \& Fay, C. L. (2008). The search for worthy leadership. Consulting Psychology Journal: Practice and Research, 60(4), 366-382.

Demerouti, E., Bakker, A. B., De Jonge, J., Janssen, P. P. M., \& Schaufeli, W. B. (2001). Burnout and engagement at work as a function of demands and control. Scandinavian Journal of Work, Environment \& Health, 27, 279-286.

Dennis, R. S., \& Bocarnea, M. (2005). Development of the servant leadership assessment instrument. Leadership and Organization Development Journal, 26, 600-615.

Evans, M. T. (1985). A Monte Carlo study of the effects of correlated method variance in moderated multiple regression analysis. Organizational Behavior and Human Decision Processes, 36, 305-323.

Fairholm, M. R., \& Fairholm, G. (2000). Leadership amid the constraints of trust. Leadership and Organization Development Journal, 21(2), 102-109.

Fiedler, F. E. (1967). A theory of leadership effectiveness. New York: McGraw-Hill.

Fombrun, C., \& Foss, C. (2004). Business ethics: Corporate responses to scandal. Corporate Reputation Review, 7(3), 284-288.

French, J., \& Raven, B. H. (1959). The bases of social power. In D. Cartwright (Ed.), Studies in social power (pp. 150-167). Ann Arbor: University of Michigan, Institute for Social Research.

Fry, L. (2003). Toward a theory of spiritual leadership. The Leadership Quarterly, 14, 693-727.

Gardner, W. L., Avolio, B. J., \& Walumbwa, F. O. (Eds.). (2005). Authentic leadership theory and practice: Origins, effects, and development. San Diego, CA: Elsevier.

Greenleaf, R. K. (1977). Servant leadership: A journey into the nature of legitimate power and greatness. New York: Paulist Press.

Greenleaf, R. K. (2002). Servant leadership: A journey into the nature of legitimate power and greatness. New York: Paulist Press.

Grenberg, J. (2005). Kant and the ethics of humility: A story of dependence, corruption and virtue. Cambridge: Cambridge University Press.

Hackett, R. D., \& Wang, G. (2012). Virtues and leadership: An integrating conceptual framework founded in Aristotelian and Confucian perspectives on virtues. Management Decision, 50(5), 868-899.

Hakanen, J. J., Bakker, A. B., \& Schaufeli, W. B. (2006). Burnout and work engagement among teachers. Journal of School Psychology, 43, 495-513.
Hayes, A. (2013). Introduction to mediation, moderation, and conditional process analysis: A regression-based approach. New York: Guilford Press.

Hersey, P., \& Blanchard, K. H. (1969). Life cycle theory of leadership. Training and Development Journal, 23(5), 26-34.

Hofstede, G. (1983). The cultural relativity of organizational practices and theories. Journal of International Business Studies, 14(2), $75-89$.

Hofstede, G. (1993). Cultural constraints in management theories. The Academy of Management Executive, 7(1), 81-94.

Hofstede, G. (n.d.). National cultural dimensions. In Countries. Retrieved March 19, 2014 from http://geert-hofstede.com

Hofstede, G., Hofstede, G. J., \& Minkov, M. (2010). Cultures and organizations: Software of the mind (3rd ed.). New York: McGraw-Hill.

House, R. J., Hanges, P. J., Javidan, M., Dorfman, P. W., \& Gupta, V. (2004). Culture, leadership, and organizations. Thousand Oaks: Sage.

House, R., Javidan, M., Hanges, P., \& Dorfman, P. (2002). Understanding cultures and implicit leadership theories across the globe: An introduction to project GLOBE. Journal of World Business, 37(1), 3-10.

Kets, D. V. M. (2004). Putting leaders on the couch. A conversation with Manfred FR Kets de Vries. Interview by Diane L. Coutu. Harvard Business Review, 82(1), 64-71.

Kline, P. (1999). The handbook of psychological testing (2nd ed.). London: Routledge.

Konczak, L. J., Stelly, D. J., \& Trusty, M. L. (2000). Defining and measuring empowering leader behaviors: Developing of an upward feedback instrument. Educational and Psychological Measurement, 60, 301-313.

Laub, J.A. (1999). Assessing the servant organization: Development of the servant organizational leadership assessment (SOLA) instrument. Dissertations Abstracts Online, 9921922.

Lewin, K., Lippit, R., \& White, R. K. (1939). Patterns of aggressive behavior in experimentally created social climates. Journal of Social Psychology, 10, 271-301.

Liden, R. C., Wayne, S. J., Zhao, H., \& Henderson, D. (2008). Servant leadership: Development of a multidimensional measure and multi-level assessment. The Leadership Quarterly, 19(2), 161-177.

Maslach, C., Schaufeli, W. B., \& Leiter, M. P. (2001). Job burnout. Annual Review of Psychology, 52, 397-422.

Morris, J. A., Brotheridge, C. M., \& Urbanski, J. C. (2005). Bringing humility to leadership: Antecedents and consequences of leader humility. Human Relations, 58(10), 1323-1350.

Muthén, L. K., \& Muthén, B. O. (2009). Mplus 5.21: Statistical analysis with latent variables [computer software]. Los Angeles, CA: Author

Nielsen, R., Marrone, J. A., \& Slay, H. S. (2010). A new look at humility: Exploring the humility concept and its role in socialized charismatic leadership. Journal of Leadership and Organizational Studies, 17(1), 33-43.

Nunnally, J. C. (1978). Psychometric theory (2nd ed.). New York: McGraw-Hill.

Nyhan, R. C. (2000). Changing the paradigm trust and its role in public sector organizations. The American Review of Public Administration, 30(1), 87-109.

Owens, B. P., \& Hekman, D. R. (2012). Modeling how to grow: An inductive examination of humble leader behaviors, contingencies, and outcomes. Academy of Management Journal, 55(4), 787-818.

Owens, B. P., Johnson, M. D., \& Mitchell, T. R. (2013). Expressed humility in organizations: Implications for performance, teams, and leadership. Organization Science, 24, 1517-1538. 
Park, N., \& Peterson, G. (2003). Virtues and organizations. In K. S. Gameron, J. E. Dutton, \& R. E. Quinn (Eds.), Positive organizational scholarship: Foundations of a new discipline (pp. 33-47). San Francisco: Berrett Koehler.

Patterson, K. (2003). Servant Leadership: A theoretical model. Doctoral dissertation, Regent University. ATT 3082719.

Pearce, C. L., \& Sims, H. P, Jr. (2002). Vertical versus shared leadership as predictors of the effectiveness of change management teams: An examination of aversive, directive, transactional, transformational, and empowering leader behaviors. Group Dynamics: Theory, Research, and Practice, 6, 172-197.

Pearce, C. L., Waldman, D. A., \& Csikszentmihaly, M. (2006). Virtuous leadership: A theoretical model and research agenda. Journal of Management, Spirituality and Religion, 3(1-2), 60-77.

Peterson, C., \& Seligman, M. E. (2004). Character strengths and virtues: A handbook and classification. Oxford: Oxford University Press.

Rahim, M. A. (1988). The development of a leader power inventory. Multivariate Behavioral Research, 23(4), 491-503.

Raven, B. H. (1965). Social influence and power. In I. D. Steiner \& M. Fishbein (Eds.), Current studies in social psychology (pp. 371-381). New York, NY: Holt, Rinehart, and Winston.

Richards, N. (1992). Humility. Philadelphia, PA: Temple University Press.

Rowatt, W., Ottenbreit, A., Nesselroade, K, Jr, \& Cunningham, P. (2002). On being holier than-thee: A social-psychological perspective on religiousness and humility. Journal for the Scientific Study of Religion, 41, 227-237.

Russell, R. F. (2001). The role of values in servant leadership. Leadership and Organization Development Journal, 22(2), 76-84.

Russell, R. F., \& Stone, A. G. (2002). A review of servant leadership attributes: Developing a practical model. Leadership and Organization Development Journal, 23, 145-157.

Sandage, S. J., \& Wiens, T. W. (2001). Contextualizing models of humility and forgiveness: A reply to Gassin. Journal of Psychology and Theology, 29, 201.

Schaufeli, W. B., \& Bakker, A. B. (2004). Job demands, job resources, and their relationship with burnout and engagement: A multi-sample study. Journal of Organizational Behavior, 25, 293-315.

Schaufeli, W. B., Bakker, A. B., \& Salanova, M. (2006). The measurement of work engagement with a short questionnaire: A cross-national study. Educational and Psychological Measurement, 66(4), 701-716.

Schaufeli, W. B., Salanova, M., González-Romá, V., \& Bakker, A. B. (2002). The measurement of engagement and burnout: A two sample confirmatory factor analytic approach. Journal of Happiness Studies, 3(1), 71-92.

Schaufeli, W. B., Taris, T. W., \& Van Rhenen, W. (2008). Workaholism, burnout and engagement: Three of a kind or three different kinds of employee well-being. Applied Psychology: An International Review, 57, 173-203.

Sendjaya, S., Sarros, J. C., \& Santora, J. C. (2008). Defining and measuring servant-leadership behaviour in organizations. Journal of Management Studies, 45, 402-424.

Snyder, N. (2010). Vision, values, and courage: Leadership for quality management. New York: Simon and Schuster. com.

Stoner, J. A., \& Freeman, R. E. (1985). Management (5th ed.). Rio de Janeiro: PHB.

Tuckey, M. R., Bakker, A. B., \& Dollard, M. F. (2012). Empowering leaders optimize working conditions for engagement: A multilevel study. Journal of Occupational Health Psychology, 17, $15-27$.

van Dierendonck, D. (2011). Servant leadership: A review and synthesis. Journal of Management, 37, 1228-1261.

van Dierendonck, D., \& Nuijten, I. (2011). The servant leadership survey: Development and validation of a multidimensional measure. Journal of Business and Psychology, 26, 249-267.

van Dierendonck, D., \& Patterson, K. (2015). Compassionate love as a cornerstone of servant leadership: An integration of previous theorizing and research. Journal of Business Ethics, 128(1), 119-131.

Vera, D., \& Rodriguez-Lopez, A. (2004). Humility as a source of competitive advantage. Organizational Dynamics, 33(4), 393-408.

Wong, P. T. P., \& Davey, D. (2007). Best practices in servant leadership. Servant leadership research roundtable-July 2007. Virginia Beach: Regent University.

Xanthopoulou, D., Bakker, A. B., Demerouti, E., \& Schaufeli, W. B. (2009). Work engagement and financial returns: A diary study on the role of job and personal resources. Journal of Occupational and Organizational Psychology, 82, 183-200.

Yukl, G. (2006). Leadership in organizations (6th ed.). Upper Saddle River, NJ: Prentice Hall. 